\title{
SELAMAT DATANG
}

PESERTA PELATIHAN CLUSTER SEKRETARIAT, DEWAN PENGAWAS

DAN UPK PNPM-MP

DI KELURAHAN KUTOANYAR Tulungagung, 14 juni 2013 


\title{
NARA SUMBER
}

\section{RACHMAD GESAH MUKTI P, SE, Ak, MM}

\author{
STAF PENGAJAR \\ FAKULTAS EKONOMI \\ UNIVERSITAS TULUNGAGUNG \\ Jln. KI. MANGUN SARKORO, BEJI \\ TULUNGAGUNG \\ No.HP.082131459405, 08161358345
}




\section{Pendahuluan}

Pengertian Perusahaan

1. Salah satu cara manusia untuk mempertahankan diri dari tekanan alam dan lingkungan

2. Lapangan yang dimanfaatkan orang untuk mempertahankan keberadaannya di dunia

3. Lapangan untuk mencukupi kebutuhan hidup manusia

4. Suatu Organisasi dimana Sumber Daya (input) dasar, seperti bahan baku \& tenaga kerja dikelola serta diproses untuk menghasilkan barang / jasa (output) kepada pelanggan 


\section{MASALAH YANG HARUS DIPECAHKAN SEBELUM SESEORANG MEMULAI OPERASI PERUSAHAANNYA}

- Keluaran (output) apa yang akan dihasilkan?

- Bentuk perusahaan apa yang didirikan?

- Berapakah jumlah modal yang dibutuhkan, dan bagaimanakah cara pemenuhan modal tersebut?

- Dimanakah lokasi perusahaan yang paling baik?

- Berapakah jumlah karyawan yang harus dipekerjakan?

- Informasi apa saja yang diperlukan perusahaan? 


\section{PROFESI AKUNTANSI DAN BIDANG SPESIALISASINYA}

Pemakaian Gelar Akuntan dan yang berhak menyandang Gelar Akuntan:

- Orang yang mempunyai ijazah Akuntan yang diberikan oleh suatu Universitas Negeri atau badan Perguruan Tinggi lain dibentuk oleh Undang-Undang atau diakui Pemerintah

- Orang yang mempunyai ijazah yang dipersamakan oleh Panitia Ahli Persamaan Ijazah Akuntan setelah lulus dalam Ujian Negara Akuntan (UNA) 


\section{PROFESI AKUNTAN}

1. AKUNTAN PRIVAT

a) Controllership

b) Akuntansi Keuangan

c) Akuntansi Biaya

d) Internall Auditing

e) Penganggaran

2. AKUNTAN PUBLIK

a) Pemeriksaan Akuntan

b) Konsultasi Manajemen

3. AKUNTAN PEMERINTAH

4. AKUNTAN PENDIDIK 


\section{PRINSIP-PRINSIP AKUNTANSI}

"Sekumpulan standar yang pada umumnya diterima dan secara universal dipraktekkan"

"Seperangkat aturan dan prosedur umum yang disebut prinsipprinsip akuntansi yang pada umumnya diterima(generally accepted accounting principles atau GAAP).

Profesi Akuntansi di Indonesia yang bergabung dalam Ikatan Akuntan Indonesia (IAI) telah berhasil menyusun GAAP yang dikenal dengan PRINSIP AKUNTANSI INDONESIA (PAI) 1984 yang disempurnakan dalam STANDAR AKUNTANSI KEUANGAN (SAK) 


\section{Pengertian Akuntansi}

"Sistem Informasi yang menghasilkan Laporan Keuangan kepada pihak-pihak yang berkepentingan mengenai kegiatan Ekonomi\&Kondisi Perusahaan".

AKUNTANSI $=$ BAHASA PERUSAHAAN 


\section{PIHAK-PIHAK PEMAKAI INFORMASI AKUNTANSI}

- Pihak yang berkepentingan langsung terhadap Perusahaan:

a)Pemilik

b)Manajemen

c) Kreditur/Calon Kreditur

d) Pemerintah

e)Karyawan 
- Pihak yang berkepentingan tidak langsung terhadap Perusahaan:
a) Analisis dan konsultan
b) Assosiasi Dagang
c) Federasi Buruh 


\section{Bidang-bidang dalam Akuntansi}

1. Akuntansi Umum/Keuangan (Finance)

2. Akuntansi Biaya (Cost)

3. Akuntansi Pemerintah / Sektor Publik (Public)

4. Akuntansi Perpajakan (Taxes)

5. Akuntansi Manajemen (Management)

6. Akuntansi Pemeriksaan (Auditing) 


\section{Proses Akuntansi}

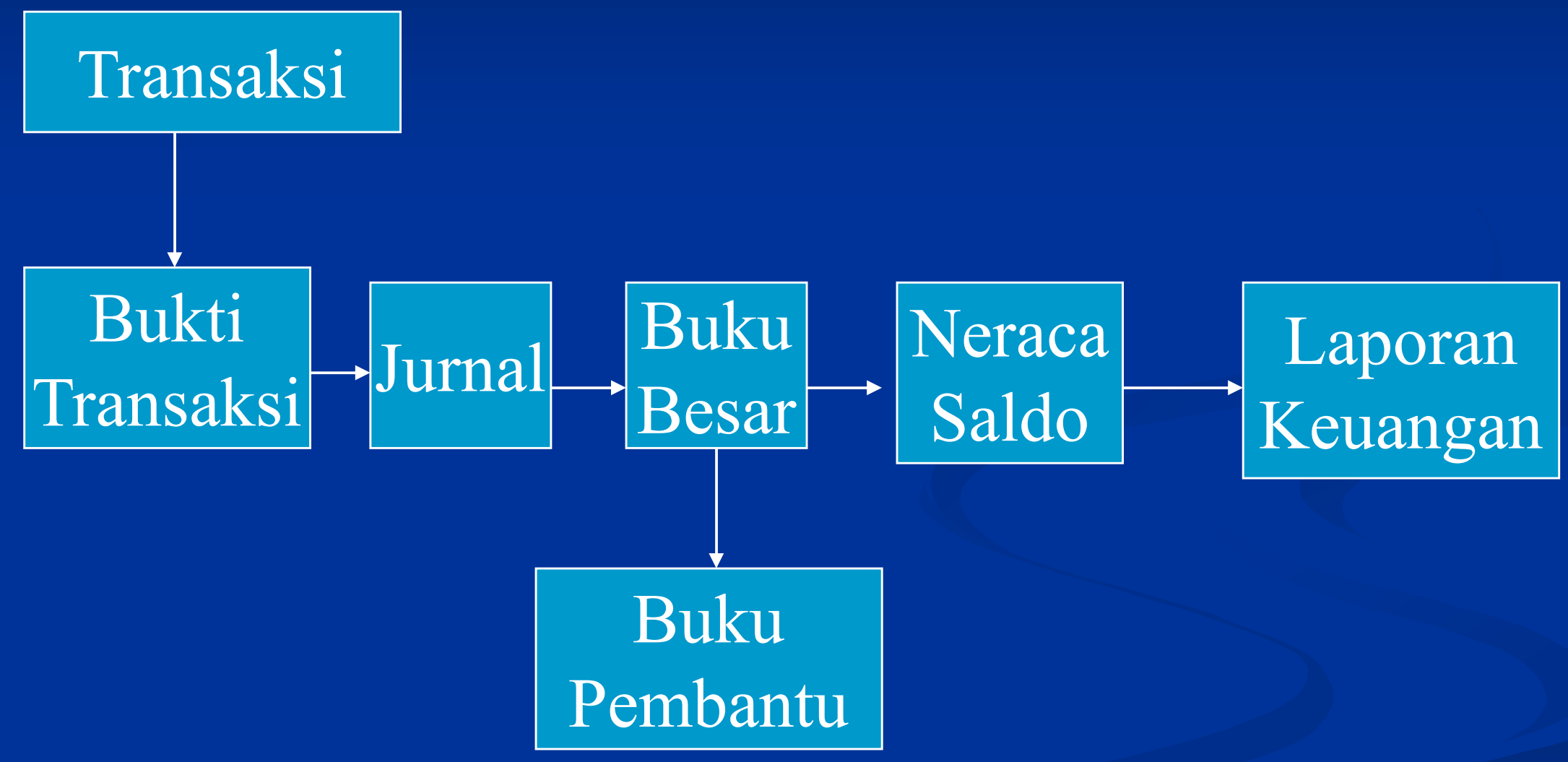




\section{Laporan Keuangan}

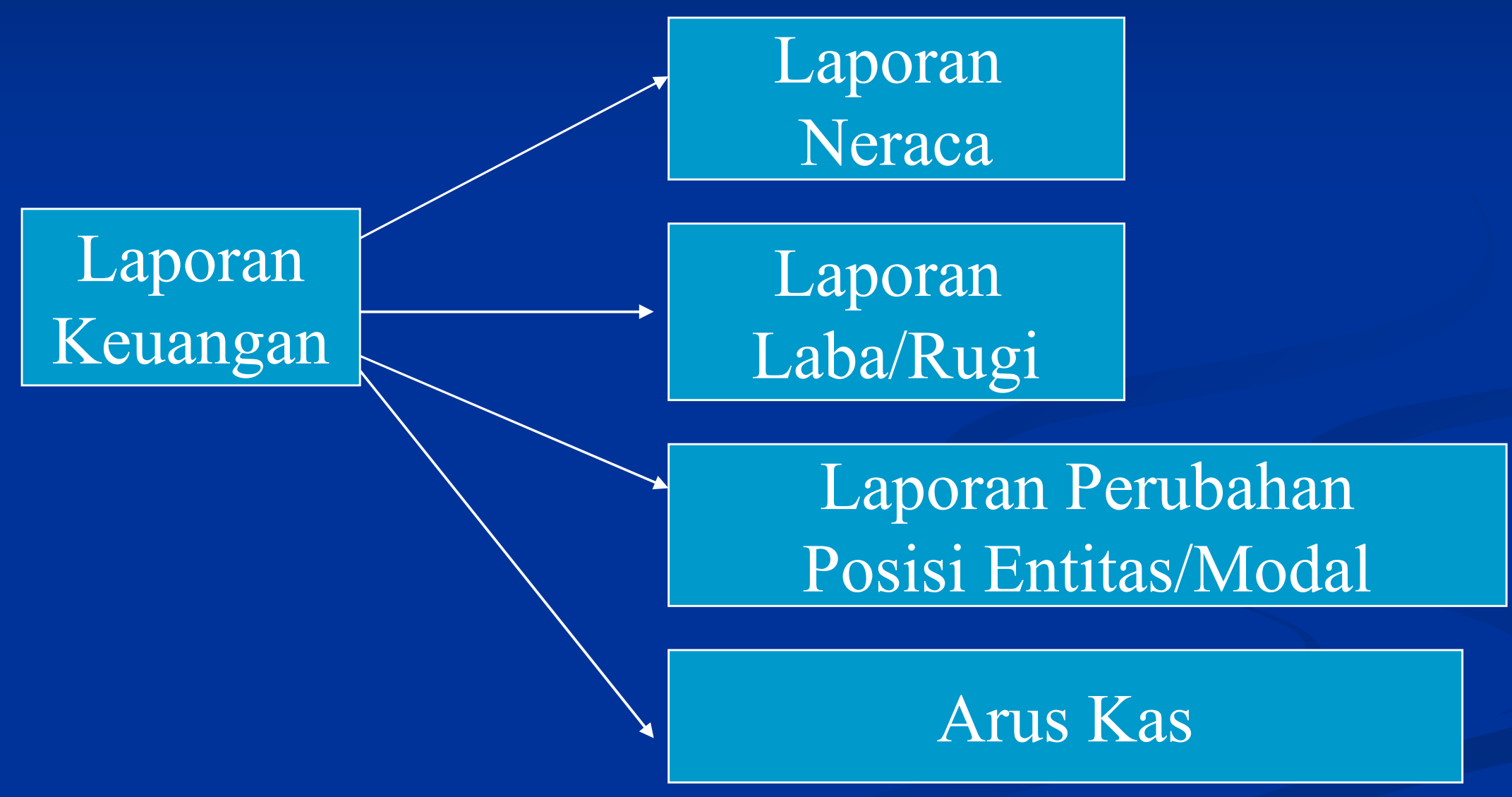




\section{Tujuan Perusahaan secara Umum}

Perusahaan didirikan dengan tujuan:

1.Mendapatkan keuntungan/Max Profit

2.Kelangsungan hidup Perusahaan/Going Concern

3.Kesejahteraan karyawan

4.Berwawasan lingkungan

"Untuk mencapai tujuan perusahaan tersebut diperlukan Sumber-sumber Ekonomis" 


\section{PERBEDAAN}

Antara AK.KOMERSIAL \& MASYARAKAT TUJUAN;

Akuntansi Komersial ; Profit Oriented

Akuntansi Masyarakat; Mengacu Ak.Pemerintahan (Ak.Sektor Publik)

1.Pertanggungawaban

2.Menajerial

3.Pengawasan 


\section{PERSAMAAN}

1. Memberikan informasi posisi keuangan dan hasil operasi

2. Mengikuti Prinsip-prinsip \& standar Akuntansi yg berlaku umum

3. Merupakan bagian terpadu dari sistem Ekonomi dan menggunakan SDM untuk mencapai tujuan

4. Menggunakan Sumber daya untuk menghasilkan barang \& jasa

5. Menghasilkan laporan keuangan untuk mengelola organisasi

6. Laporan Keuangan yg dihasilkan merupakan informasi untuk proses pengambilan keputusan 


\section{Sumber-sumber Ekonomis Perusahaan}

Dalam Akuntansi istilah sumber Ekonomis disebut AKTIVA (ASSET) "Kekayaan yang dimiliki oleh Perusahaan"

Sedangkan Klaim atas AKTIVA adalah PASIVA "Hak atas kekayaan tersebut"

$$
\text { AKTIVA=PASIVA }
$$




\section{PASIVA berasal dari :}

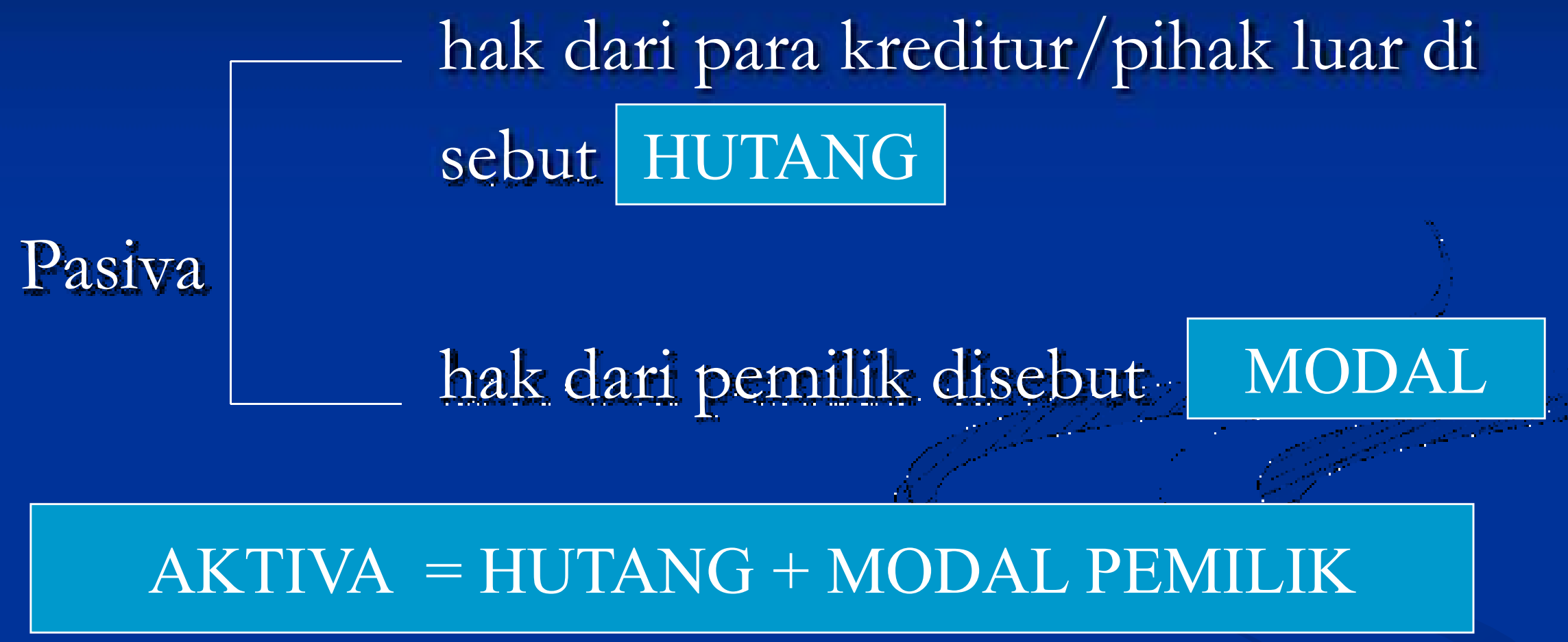

MODAL = AKTIVA -HUTANG 


\section{Prosedur Pembukuan}

Rekening/Perkiraan/Account :

"Suatu alat untuk mencatat transaksi-transaksi

$$
\begin{aligned}
& \text { keuangan yang berkaitan dengan Aktiva, } \\
& \text { Hutang,Modal, Penghasilan dan Biaya-biaya" }
\end{aligned}
$$

Trujuan :

"Untuk mencatat data-data yang akan menjadi dasar penyusunan laporan-laporan keuangan" 
Kumpulan-kumpulan rekening disebut: "Buku Besar/LEDGER"

Jumlah rekening dalam pembukuan suatu. perusahaan tergantung kepada kebutuhan perusahaan. 


\section{Rekening-rekening dalam Buku besar}

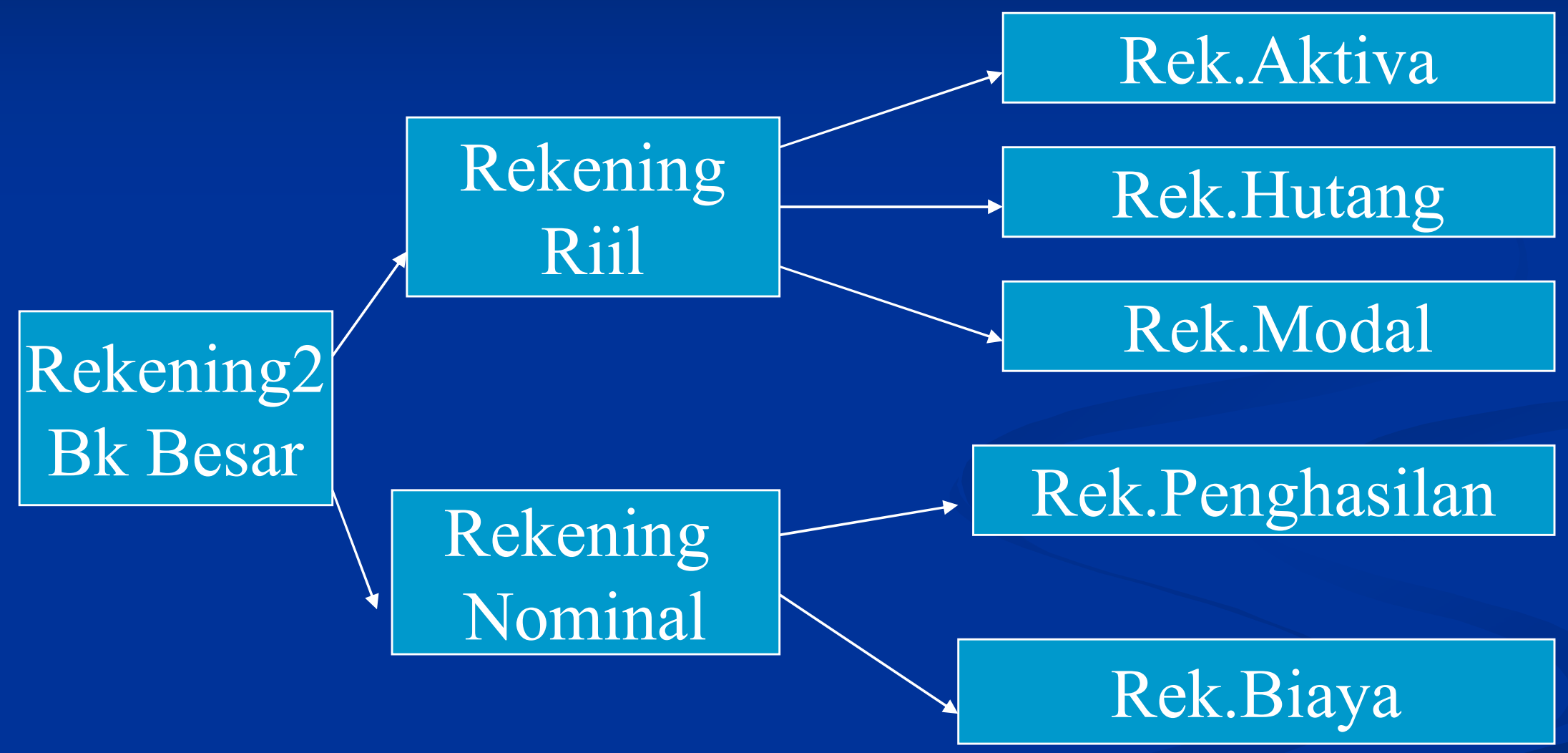




\section{Bentuk Rekening}

Bentuk rekening secara umum disebut T Account Atau rekening bentuk $\mathrm{T}$ :

DEBET

KREDIT

\begin{tabular}{|c|c|c|c|c|c|}
\hline Tgl & Keterangan/Uraian & Jumlah & Tgl & Keterangan/Uraian & Jumlah \\
\hline & & & & & \\
& & & & & \\
& & & & & \\
\hline
\end{tabular}




\section{Pembukuan pada PNMP-MP}

1.SEKRETARIAT ; S1 BUKU BANK

S2 BUKU KAS

S3 BUKU LINGKUNGAN

S4 BUKU SOSIAL

S5 BUKU EKONOMI BERGULIR

S6 BUKU BIAYA OPERASIONAL(BOP)

S7 BUKU INVENTARIS

S8 BUKU

S9 BK PEMASUKAN \& PENGELUARAN

N E R A C A 
2.UPK ;

1.CatatanUANG MASUK
2.CatatanUANG KELUAR
3.BUKU KAS
4.BUKU BANK
5.BUKU INVENTARIS
6.BUKU BESAR \& NERACA SALDO
7.BUKU PENDAPATAN \& BIAYA
8.LAPORAN LABA/RUGI
9.NERACA
10.BUKU MEMORIAL




\section{Proses Pemeriksaan (Audit)}

1. Laporan Keuangan

2. Buku Besar \& Neraca Saldo

3. Buku Pendapatan \& Biaya

4. Buku-buku catatan

5. Dokumen/bukti transaksi (BKMsk \& BKK) 


\section{ALUR DANA BKM/LKM}

APBN APBD \& SUMBER PENDANAAN PIHAK LAIN

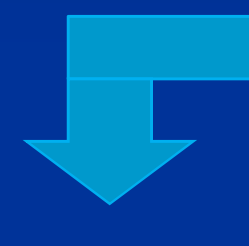

UNIT PENGELOLA LINGKUNGAN

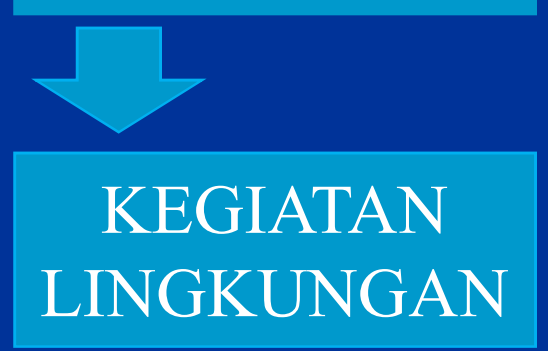
$\checkmark$

\section{SEKRETARIAT}

$\checkmark$

UNIT PENGELOLA KEUANGAN
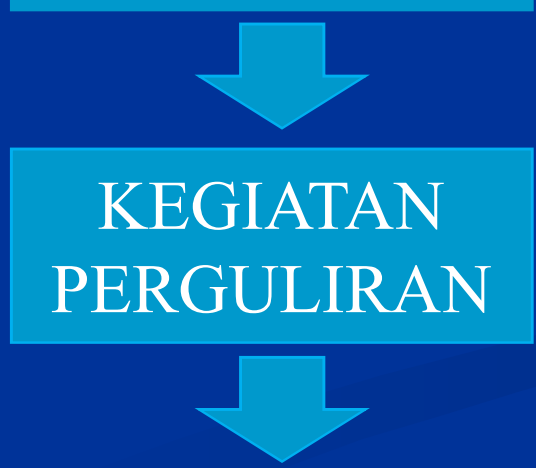

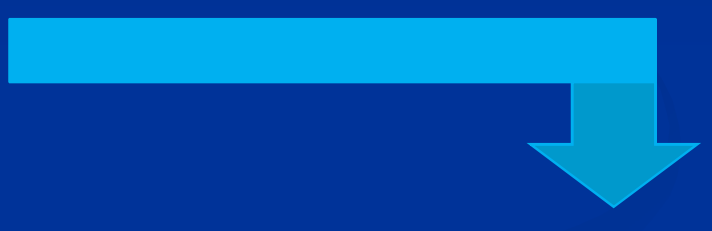

UNIT PENGELOLA SOSIAL

KEGIATAN SOSIAL 


\section{SISTEM PEMBUKUAN SEKRETARIAT}

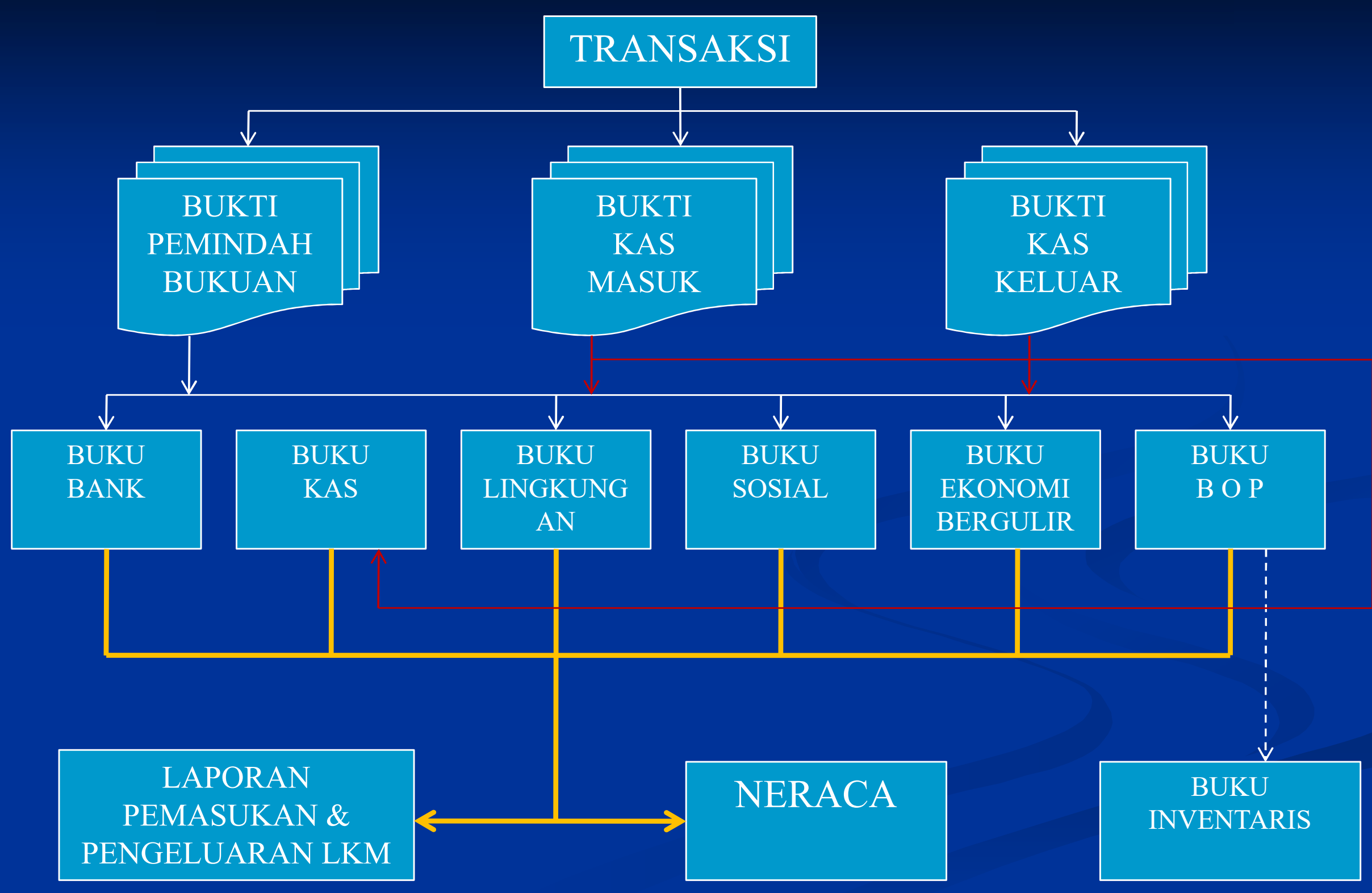


SISTEM PEMBUKUAN UPK

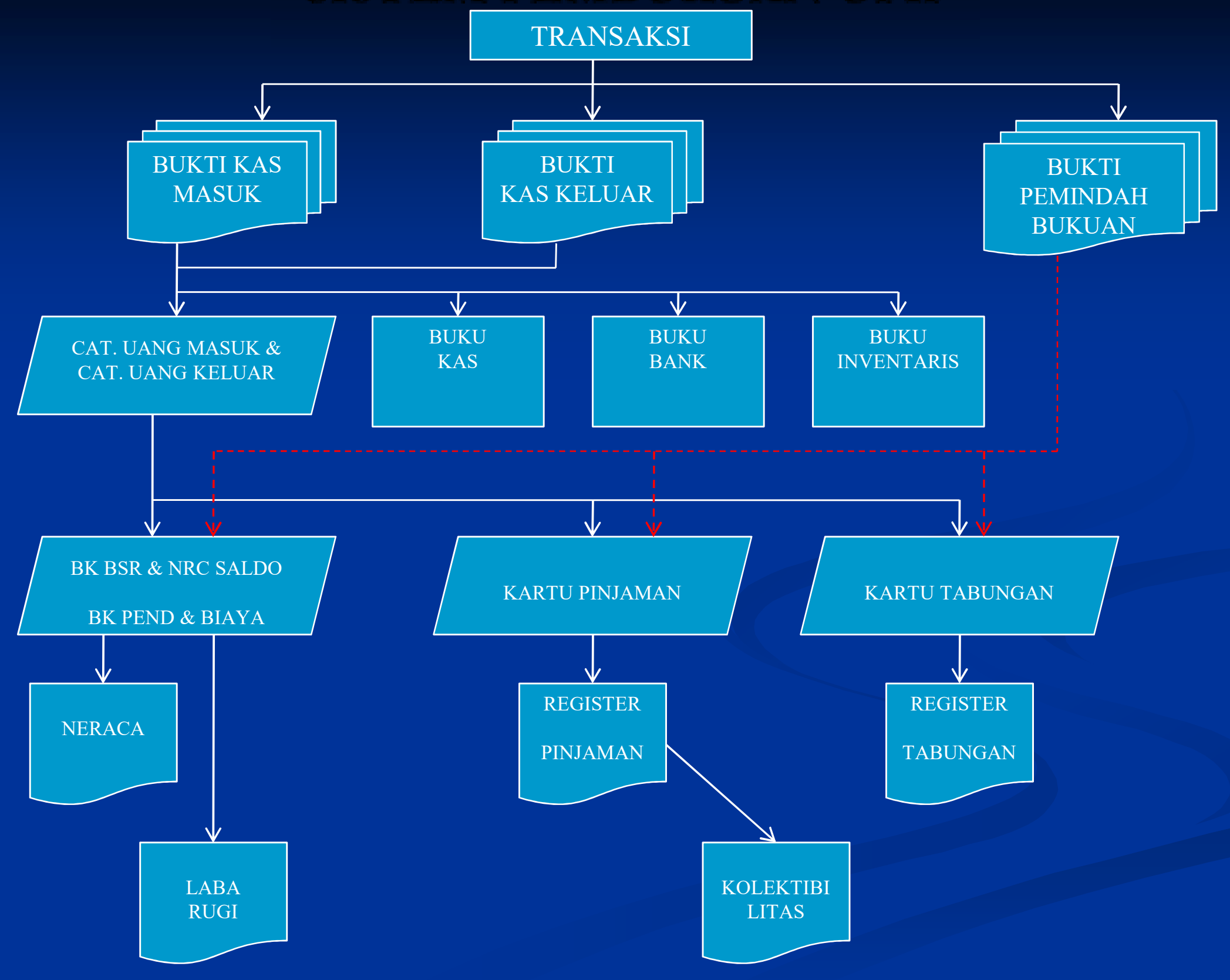




\section{PINJAMAN BERGULIR}

PENGERTIAN:

PINJAMAN DALAM PNPM MANDIRI PERKOTAAN YANG DIBERIKAN KEPADA MASYARAKAT MISKIN MELALUI KELOMPOK SWADAYA MASYARAKAT (KSM) UNTUK MENINGKATKAN PENDAPATAN DAN KESEJAHTERAANNYA.

TUJUAN:

a. MENYEDIAKAN AKSES LAYANAN KEUANGAN KEPADA RUMAH TANGGA MISKIN DENGAN PINJAMAN MIKRO BERBASIS PASAR DENGAN KEGIATAN YANG MENGHASILKAN PENDAPATAN.

b. MEMPERBAIKI KONDISI EKONOMI RUMAH TANGGA MISKIN DAN KEGIATAN YANG MENDUKUNG TUMBUHNYA EKONOMI SERTA USAHA MIKRO.

c. MEMBERIKAN PEMBELAJARAN DALAM HAL MENGELOLA PINJAMAN DAN MENGGUNAKANNYA SECARA BENAR. 
SASARAN:

SASARAN UTAMANYA ADALAH RUMAH TANGGA MISKIN DI WILAYAH DESA / KELURAHAN DIMANA BKM / LKM BERADA, KHUSUSNYA WARGA MISKIN YANG SUDAH TERCANTUM DALAM DAFTAR WARGA MISKIN (HASIL PEMETAAN SWADAYA / PS-2).

PEMINJAM:

ADALAH KELOMPOK SWADAYA MASYARAKAT (KSM) YANG TELAH MEMENUHI KRITERIA, YAITU:

a. WARGA MISKIN YANG TERCANTUM DALAM PS-2.

b. PUNYA USAHA ATAU AKAN MULAI BUKA USAHA.

c. USAHANYA MENGUNTUNGKAN DAN DAPAT DIKEMBANGKAN.

d. PUNYA MOTIVASI UNTUK MENGEMBANGKAN USAHA.

e. MEMERLUKAN TAMBAHAN MODAL KERJA.

f. PUNYA KEMAUAN DAN KEMAMPUAN MENGEMBALIKAN PINJAMAN.

g. MENDAPAT PERSETUJUAN KELUARGA.

h. USAHANYA TIDAK BERTENTANGAN DENGAN UNDANG-UNDANG, PERATURAN DAN KESUSILAAN. 


\section{SKEMA TAHAP PEMBERIAN PINJAMAN}

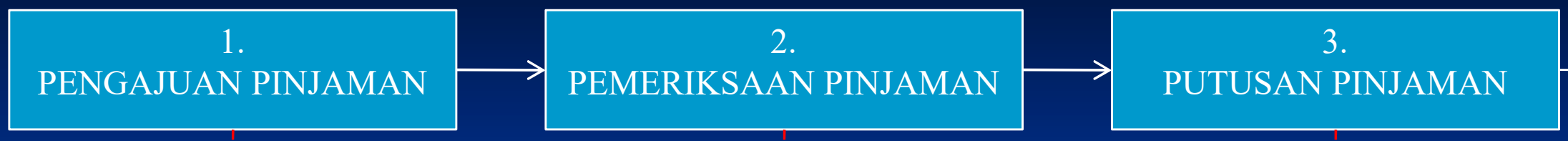

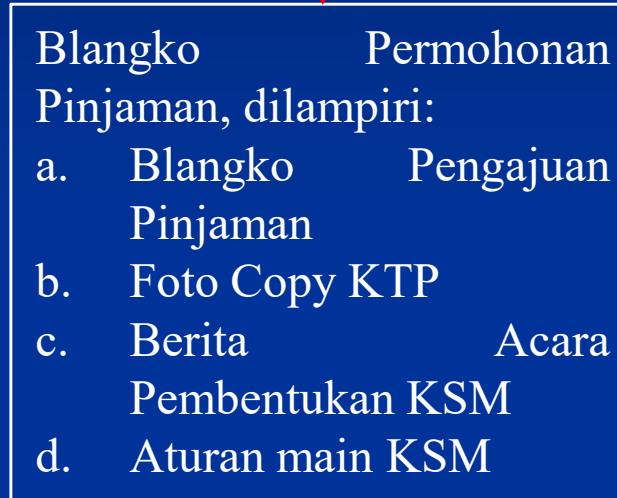
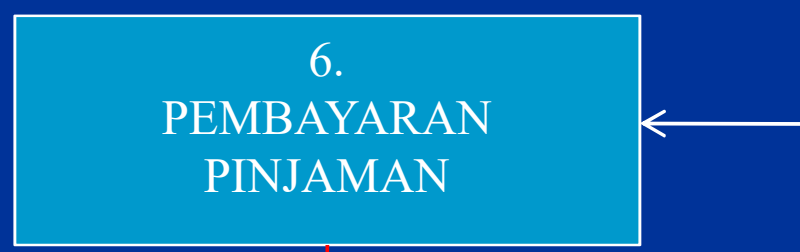

a. Analisis Pinjaman
b. Usulan Pinjaman

Putusan (Persetujuan /
$\begin{aligned} & \text { Penolakan) } \\ & \text { Pinjaman }\end{aligned}$

Pinjaman

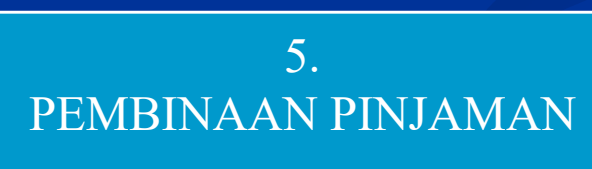

Catatan Hasil Pembinaan Pinjaman
4.

REALISASI PINJAMAN a. Kartu Pinjaman

b. Bukti Kas Masuk

c. Kartu Tabungan

\begin{tabular}{|ll|}
\hline a. & Surat Perjanjian \\
& Pinjaman \\
b. & Bukti Kas Keluar \\
c. & Kartu Pinjaman \\
\hline
\end{tabular}




\section{MONITORING PINJAMAN BERGULIR}

AGAR TUJUAN PEMBERIAN PINJAMAN BERGULIR INI TERCAPAI DENGAN KUALITAS YANG BAIK, MAKA MONITORING TERHADAP PINJAMAN BERGULIR INI WAJIB DILAKUKAN SECARA BERKESINAMBUNGAN DAN TERARAH.

KEGIATAN MONITORING DILAKUKAN DENGAN MEMPERHATIKAN INDIKATOR UTAMAKINERJA KEUANGAN PINJAMAN BERGULIR DAN PENCAPAIAN SASARAN.

MONITORING PINJAMAN BERGULIR TERDIRI DARI:

a. MONITORING ADMINISTRATIF.

b. MONITORING LAPANGAN. 


\section{MONITORING \\ ADMINISTRATIF}

KEGIATAN MONITORING ADMINISTRATIF DILAKUKAN OLEH PENGAWAS UPK DAN MANAJER UPK DENGAN MELIHAT 4 INDIKATOR UTAMA KINERJA KEUANGAN, YAITU:

a. LAR = MENUNJUKKAN PERSENTASE PEMINJAM MENUNGGAK.

b. PAR = MENUNJUKKAN PERSENTASE PINJAMAN YANG TERTUNGGAK.

c. $\quad$ ROI = KEMAMPUAN UPK DALAM MENGHASILKAN LABA DARI MODAL YANG DIPERGUNAKAN UNTUK PINJAMAN BERGULIR.

d. $\mathrm{CCr}=$ KEMAMPUAN UPK UNTUK MENUTUP BIAYA DARI PENDAPATAN YANG DIPEROLEHNYA.

KEGIATAN MONITORING ADMINISTRATIF INI SEBAIKNYA DILAKUKAN MINIMAL SEBULAN SEKALI 


\section{MONITORING LAPANGAN}

MONITORING LAPANGAN DILAKUKAN OLEH PENGAWAS SECARA BERKALA MINIMAL SEBULAN SEKALI DENGAN UJI PETIK YANG MENGARAH KESELURUH PEMINJAM. APABILA DITEMUKAN KASUS / PENYIMPANGAN MAKA DILAKUKAN PEMERIKSAAN KHUSUS UNTUK MENYELESAIKAN KASUS TERSEBUT ATAU UNTUK MENEMUKAN APAKAH ADA KASUS LAIN DISAMPING YANG SUDAH DIKETEMUKAN.

TUJUAN MONITORING LAPANGAN:

a. AGAR TIDAK TERJADI PENYIMPANGAN DALAM PEMBERIAN PINJAMAN.

b. UNTUK MENGETAHUI PERKEMBANGAN USAHA / KESEJAHTERAAN PEMINJAM.

c. AGAR TIDAK TERJADI KETERLAMBATAN PEMBAYARAN KEMBALI.

d. UNTUK MENGINTENSIFKAN PENAGIHAN PEMBAYARAN KEMBALI BAGI YANG MENUNGGAK.

e. APABILA SUDAH DITEMUKAN KASUS, APAKAH MASIH ADA KASUS LAIN YANG SERUPA ATAU BERBEDA DARI YANG TELAH DIKETEMUKAN. 


\section{PENANGANAN PINJAMAN BERMASALAH}

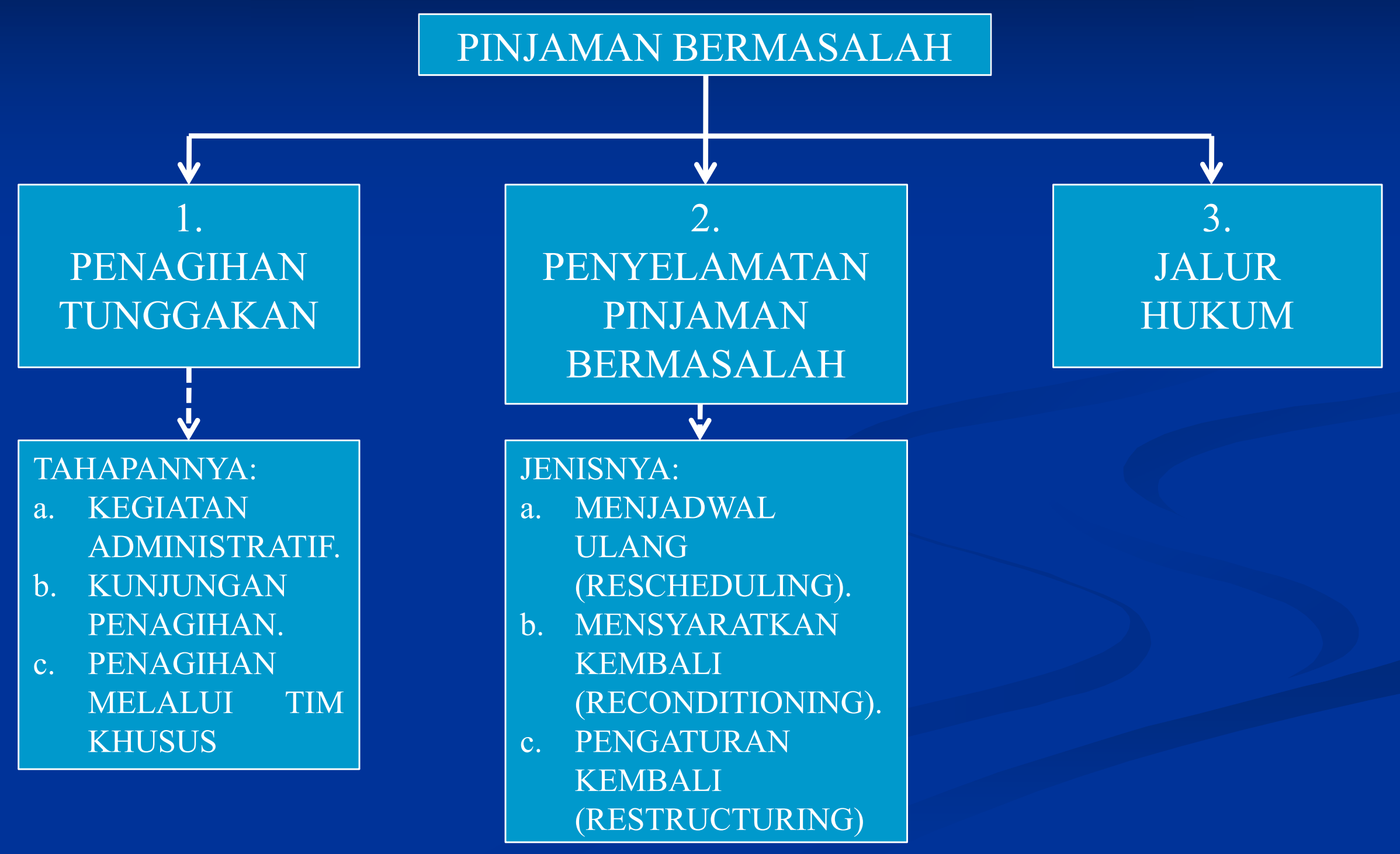




\section{TERIMA KASIH}

PUSAT PENELITIAN DAN PENGABDIAN MASYARAKAT FAKULTAS EKONOMI (P3MFE) UNIVERSITAS TULUNGAGUNG www.unita.ac.id fakultasekonomiunita@gmail.com 